See Article page 61 in the September 2020 issue.

\section{Commentary: Watchful waiting during visceral malperfusion in DeBakey type I aortic dissection: A possible paradigm shift?}

\author{
Aleksander Dokollari, MD, ${ }^{\mathrm{a}}$ and \\ Gianluigi Bisleri, $\mathrm{MD}^{\mathrm{b}}$
}

DeBakey type I aortic dissection is an emergent medical condition, especially when the distal extension of the disease leads to potential visceral malperfusion. The goals of the surgical intervention in DeBakey type I aortic dissection, while primarily aimed at managing the proximal portion of the aorta, include the resolution of the dynamic flow obstruction and depressurization of the false lumen also in the distal segments, especially if visceral malperfusion is present. In the September 2020 issue, Preventza and colleagues ${ }^{1}$ present a case of DeBakey type I aortic dissection with visceral malperfusion that was managed first by using the PETTICOAT (Provisional Extension to Induce Complete Attachment) technique to resolve the malperfusion syndrome and then followed by replacement of the root/ascending aorta/hemiarch 6 days after the index procedure.

The presence of preoperative malperfusion in acute aortic dissection has been previously demonstrated to represent a significant incremental risk factor for perioperative mortality, as reported by Czerny and colleagues ${ }^{2}$ : in particular, the GEERAADA (German Registry for Acute Aortic Dissection Type A) registry identified cerebral, coronary, renal, and peripheral extremity ischemia being the most common types of preoperative malperfusion, and likely to be found in $10 \%$ of patients, whereas mesenteric and spinal ischemia were less-common findings. In the

\footnotetext{
From the ${ }^{\mathrm{a}}$ Division of Cardiac Surgery, St Michael's Hospital, Toronto; and ${ }^{\mathrm{b}}$ Division of Cardiac Surgery, Queen's University, Kingston, Ontario, Canada.

Disclosures: The authors reported no conflicts of interest.

The Journal policy requires editors and reviewers to disclose conflicts of interest and to decline handling or reviewing manuscripts for which they may have a conflict of interest. The editors and reviewers of this article have no conflicts of interest.

Received for publication Aug 15, 2020; revisions received Aug 15, 2020; accepted for publication Aug 21, 2020; available ahead of print Sept 2, 2020.

Address for reprints: Gianluigi Bisleri, MD, Kingston General Hospital, Victory 3, 76 Stuart St, Kingston, Ontario, K7L 2V7, Canada (E-mail: Gianluigi.bisleri@ queensu.ca).

JTCVS Techniques 2020;4:81-2

2666-2507

Copyright (C) 2020 The Authors. Published by Elsevier Inc. on behalf of The American Association for Thoracic Surgery. This is an open access article under the CC BY-NCND license (http://creativecommons.org/licenses/by-nc-nd/4.0/).

https://doi.org/10.1016/j.xjtc.2020.08.054
}

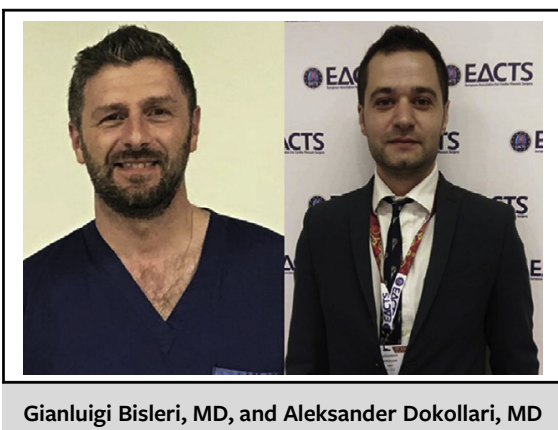

$$
\begin{aligned}
& \text { CENTRAL MESSAGE } \\
& \text { The staged approach can repre- } \\
& \text { sent an important option for the } \\
& \text { management of DeBakey type I } \\
& \text { aortic dissection; nevertheless, a } \\
& \text { word of caution is warranted } \\
& \text { regarding the ideal time frame. }
\end{aligned}
$$

current case, the preoperative presence of dynamic malperfusion of the celiac, superior mesenteric, and right renal arteries detected by the computed tomography scan along with increased level of lactates (up to $8.3 \mathrm{mmol} / \mathrm{L}$ ) led the authors to focus first on resolving the visceral malperfusion and then addressing the disease at the level of the root/ascending aorta.

The authors should be praised for the innovative use of the Zenith Dissection Endovascular system to resolve the visceral malperfusion instead of using fenestration between the true and false lumen or stenting the visceral arteries.

This staged approach can represent an important option for the management of this complex and extremely highrisk subset of patients; nevertheless, a word of caution is warranted regarding the ideal time frame for such staged strategy, especially if excessively prolonged: in the present case, lactic acidosis normalized within 48 hours and therefore a shorter time frame could also have been appropriate, especially to mitigate the potential catastrophic effects of a dissected ascending aorta and root over several days. While the final outcome was successful in the present case, the postoperative right ventricular dysfunction (due to the dissection involving the right coronary artery) along with the extracorporeal membrane oxygenation requirement could suggest that a timely intervention to the proximal segments of the aorta should be advisable as soon as the biochemical and clinical findings corroborate a resolution of the visceral malperfusion. 
The management of aortic dissection, especially in the presence of visceral malperfusion, still remains a major clinical challenge: this report nicely contributes to the limited evidence available so far and offers a novel potential therapeutic option that warrants further clinical validation.

\section{References}

1. Preventza O, Olutoye OO II, Chatterjee S, Le Huu A, Coselli J. Provisional extension to induce complete attachment of an endovascular repair for acute type A aortic dissection with visceral malperfusion. J Thorac Cardiovasc Surg Tech. 2020;3C:61-3.

2. Czerny M, Schoenhoff F, Etz C, Englberger L, Khaladj N, Zierer A, et al. The impact of pre-operative malperfusion on outcome in acute type A aortic dissection: results from the GERAADA registry. J Am Coll Cardiol. 2015;65:2628-35. 